\title{
Electrochemical Deposition of Hierarchical Micro/Nanostructures of Copper Hydroxysulfates on Polypyrrole-Polystyrene Sulfonate Films
}

\author{
Enrico Andreoli, ${ }^{*}{ }^{+}$Denise A. Rooney, ${ }^{\dagger}$ Wynette Redington, ${ }^{\neq}$Robert Gunning, ${ }^{\ddagger}$ and Carmel B. Breslin ${ }^{\dagger}$ \\ ${ }^{\dagger}$ Department of Chemistry, National University of Ireland Maynooth, Co. Kildare, Maynooth, Ireland \\ ${ }^{\ddagger}$ Materials and Surface Science Institute, University of Limerick, Co. Limerick, Limerick, Ireland \\ Supporting Information
}

ABSTRACT: Copper-based hierarchical micro/nanostructures were prepared using a novel electrochemical route on polypyrrole-polystyrene sulfonate (PPy-PSS) thin films. The resulting structures are composed of copper hydroxysulfates, as confirmed by the electrochemical, spectroscopic, and X-ray diffraction characterization. The electrochemistry of the film is a key factor in the overall deposition of the micro/nanostructures. The PPy-PSS films capture cations from the copper sulfate electrolyte solution and facilitate the reduction of dissolved oxygen to hydroxide ions. The system then acts like a nanoreactor as the $\mathrm{Cu}^{2+}$ and $\mathrm{OH}^{-}$ions are concentrated on the polymer surface, which in the presence of the $\mathrm{SO}_{4}{ }^{2-}$ ions from the electrolyte solution results in the electrocrystallization of the copper hydroxysulfates hierarchical structures.

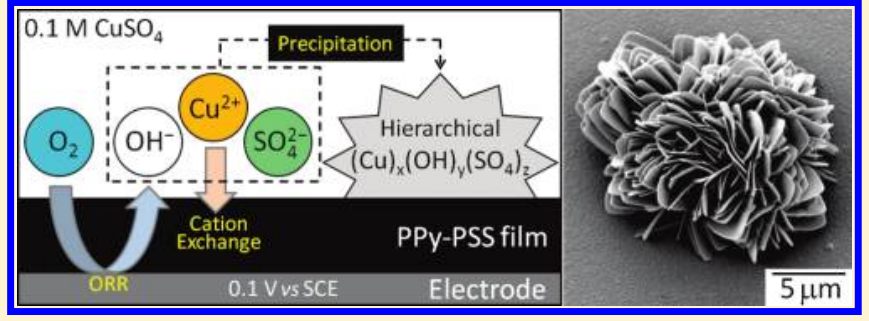

\section{INTRODUCTION}

The controlled deposition of nanomaterials is a compelling challenge for modern technology. The possibility of reproducing existing or creating novel devices at the micro/nanoscale is strongly related to the availability of appropriate building tools. ${ }^{1}$ Electrochemical techniques, among several others, are attractive because of the use of relatively inexpensive equipment and the ease of the procedures. This is especially true when an electrochemical approach results in a synthetic route to nanomaterials which is rapid, simple, templateless, and surfactantless. Engineered multidimensional nanomaterials with well-defined shape and structure are also attracting much interest because of their potential use in many different areas such as environmental analysis and monitoring, drug delivery and tissue engineering, cell imaging and treatment, and renewable energy technologies. ${ }^{2-5}$ The use of conducting polymers in the design and construction of micro/nanoarchitectures is interesting because of the possibility of controlling the morphology through the polymer properties and the electrode potential. Some examples of electrochemical deposition of copper-based nanostructures on polypyrrole films are available in the literature. Copper nanoclusters, made of $\mathrm{Cu}_{2} \mathrm{O}$, have been prepared on polypyrrole films doped with chloride anions. ${ }^{6}$ Copper fractals, nanowires, and nanocrystals were formed by galvanostatic deposition on polypyrrole doped with perchlorate anions, ${ }^{7}$ whereas self-assembled nanostructures were formed through potentiostatic deposition. ${ }^{8}$ With the latter system the size of the copper nanocrystals could be changed with the polymer thickness, and on ultrathin films a regular decrease of the particle size was observed with a decrease of the electrode potential. ${ }^{9}$ However, as of yet, to the best of our knowledge there are no reports on the electrosynthesis of flowerlike copper-based hierarchical structures at polypyrrole or at any other conducting polymer films. Hierarchical copper-based micro/nanostructures are usually prepared hydrothermally in alkaline solutions. Typically, the preparation takes from hours to days, depending on the temperature and concentration of the base. The majority of the hierarchical copper structures are made of copper oxides, ${ }^{10-12}$ copper sulfides, ${ }^{13-15}$ or their mixtures. ${ }^{16}$ These materials can be used in several applications, such as supercapacitors, ${ }^{17}$ gas sensors, ${ }^{18}$ for the removal of pollutants, ${ }^{19}$ for the preparation of superhydrophobic surfaces, ${ }^{12,16,20}$ and as anodes for lithium-ion batteries. $^{21}$ Other hierarchical materials are obtained from the basic salts of copper, for example, from copper hydroxyphosphates, ${ }^{22}$ copper hydroxycarbonates, ${ }^{23}$ or copper hydroxysulfates. ${ }^{24}$ The development of suitable applications for these materials has received limited consideration until recently, when industrial applications were considered for layered hydroxide salts. ${ }^{25}$

Polypyrrole-polystyrene sulfonate (PPy-PSS) films have been already used for the electrodeposition of copper, and the metallization was described as a two-step process. ${ }^{26-28}$ First the copper ions are incorporated into the film and then reduced to metallic copper. In general copper and polypyrrole interact either through a copper-nitrogen or a copper-oxygen complex formation depending on the nature of the dopant and on the experimental conditions. Spectroscopic evidence of $\mathrm{Cu}-\mathrm{PPy}$ complexation has been found in polymers doped with small ions within which copper interacts directly with the pyrrolic

Received: January 16, 2011

Revised: March 19, 2011

Published: April 12, 2011 
nitrogen. ${ }^{29-32}$ The interaction between copper and pyrrolic nitrogen has been recently observed for copper ions onto nanothin PPy films. ${ }^{33} \mathrm{Cu}$-dopant interactions have been found in the presence of sulfated dopants where copper is bound to the $-\mathrm{OSO}_{3}{ }^{-}$ groups. ${ }^{34,35}$ PPy-PSS composite films have been studied in great detail. Since the PSS sulfonate groups are irreversibly incorporated in the polymer matrix, the films behave as redox cation exchangers. The cation influx into and efflux from the films have been studied previously using electrochemical quartz crystal microbalance ${ }^{36,37}$ and rotating ring disk electrode, ${ }^{38}$ while electron spectroscopy for chemical analysis measurements showed that the cations are present only on the surface of the reduced form of the film. ${ }^{39}$

In this paper, a novel synthetic route is presented and applied to the deposition of copper hydroxysulfate-based hierarchical micro/nanostructures at the PPy-PSS thin films. These structures are formed following the occurrence of two simultaneous processes, namely, the capture of $\mathrm{Cu}^{2+}$ and formation of $\mathrm{OH}^{-}$ both promoted by the PPy-PSS film. The $\mathrm{Cu}^{2+}$ and $\mathrm{OH}^{-}$ions are concentrated on the polymer surface, which in the presence of the $\mathrm{SO}_{4}{ }^{2-}$ anions from the electrolyte solution allows the electrocrystallization of the hierarchical micro/nanostructures. These structures may have applications as metal oxide precursors, selective ion scavengers, and/or templates for the formation of nanoparticles. ${ }^{25}$

\section{EXPERIMENTAL SECTION}

a. Materials. The chemicals used in the present work were pyrrole (98\%), poly(sodium 4-styrenesulfonate), $M_{\mathrm{w}} \sim 70000$ $\mathrm{g} / \mathrm{mol}$, sodium sulfate $(\geq 99.0 \%)$, copper sulfate pentahydrate (99.999\%), and zinc sulfate heptahydrate $(\geq 99.0 \%)$. Water was distilled and Milli-Q purified in the laboratory $(14 \mathrm{M} \Omega \cdot \mathrm{cm}$, $\mathrm{pH}=5.0)$. All chemicals were supplied by Sigma-Aldrich. High purity nitrogen and oxygen gases (99.95\%) were supplied by BOC Ireland.

b. Preparations. A stock amount of pyrrole (Py) was vacuumdistilled and stored in the dark at $-20^{\circ} \mathrm{C}$ under nitrogen. The polypyrrole-polystyrene sulfonate (PPy-PSS) thin films were prepared with a standard three-electrode cell on glassy carbon $\left(\mathrm{GC}, 0.126 \mathrm{~cm}^{2}\right)$ and gold $\left(\mathrm{Au}, 0.200 \mathrm{~cm}^{2}\right)$ disk electrodes. The counter electrode was a platinum wire, and the reference electrode a saturated calomel electrode (SCE, all potentials in the tables are referred to SCE). The electrolyte solution was made of $0.15 \mathrm{M}$ Py and $50 \mathrm{mM}$ PSS (calculated from the molecular weight of the monomer unit) dissolved in Milli- $Q$ water. The polymer was grown at a constant potential of $0.60 \mathrm{~V} \mathrm{vs}$ SCE to give uniform thin films. The electropolymerizations were stopped after a certain charge was reached, usually $40 \mathrm{mC} / \mathrm{cm}^{2}$. The thickness of the PPy-PSS films was calculated as $120 \mathrm{~nm}$ using a volume-to-charge ratio of $3.00 \times 10^{-4} \mathrm{~cm}^{3} / \mathrm{C}^{40}$ The copper-based micro/nanostructures were formed electrochemically on the surface of the PPy-PSS films. After the electropolymerization, the electrodes were thoroughly rinsed with Milli$\mathrm{Q}$ water and immersed in a $0.10 \mathrm{M} \mathrm{CuSO}_{4}$ solution. The potential of the electrode was set at a constant value of $0.10 \mathrm{~V}$ vs SCE until a certain charge was passed (usually $40 \mathrm{mC} / \mathrm{cm}^{2}$ ) and the copper-based structures were formed. The potentiostatic deposition was performed with solutions that were either used as prepared in air or saturated with oxygen. In the latter case, a copper sulfate solution was bubbled and stirred with high purity oxygen for at least $60 \mathrm{~min}$ prior to the electrodeposition. The same was done with nitrogen in order to evaluate the effect of

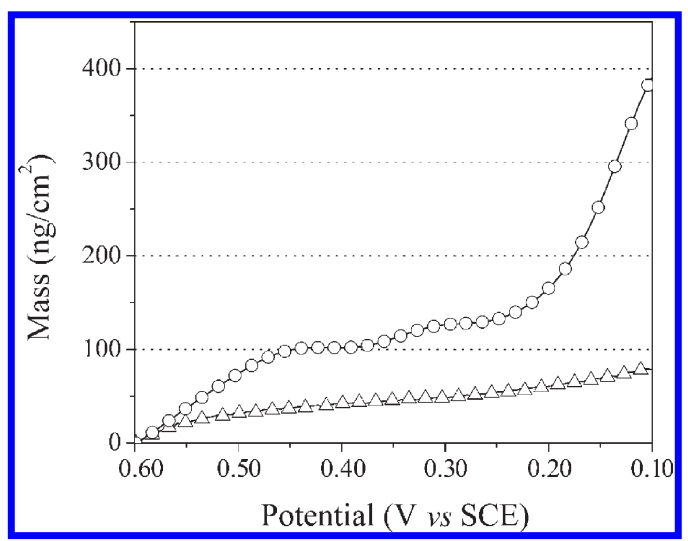

Figure 1. Mass changes recorded at a PPy-PSS film in aerated $0.10 \mathrm{M}$ $\mathrm{CuSO}_{4}(-\mathrm{O}-)$ or $0.10 \mathrm{M} \mathrm{NaPSS}(-\triangle-)$ upon applying a reduction potential sweep from 0.60 to $0.10 \mathrm{~V}$ vs SCE at a scan rate of $10 \mathrm{mV} / \mathrm{s}$.

oxygen on the deposition of the micro/nanostructures. Once the deposition was completed, the working electrodes were extensively rinsed with Milli-Q water and left to dry.

c. Equipment. The electrochemical experiments were performed with a Solartron 1285 potentiostat. The rotating disk electrode was a Pine MRS Rotor System equipped with glassy carbon E3 Series RDE tip. The electrochemical quartz crystal microbalance was a $\mathrm{CH}$ Instrument $400 \mathrm{~A}$ equipped with a CH127 cell and CH125A gold crystal electrodes (polished, bounded, and mounted, $100 \AA \mathrm{Ti}+1000 \AA \mathrm{Au}$ ). The scanning electron microscopy characterization was performed with a Hitachi S-3200-N equipped with an Oxford Instrument INCAx-act EDX system and a Hitachi S-4000 with a cold cathode field emission electron source (FE-SEM) equipped with Princeton Gamma Technology Avalon 8000 EDX system. The samples were sputter-coated with gold or gold/palladium ultrathin films with an AGAR Automatic Sputter Coater equipped with an AGAR Terminating Film Thickness Monitor unit. The infrared spectroscopy characterization was performed with a Varian FTS-7000 FT-IR equipped with a Pike Miracle ATR built in diamond crystal. The depth of penetration of the crystal at $45^{\circ}$ was $2.0 \mu \mathrm{m}$. The X-ray photoelectron spectroscopy equipment was a Kratos Axis 165 equipped with a monochromatic $\mathrm{Al}$ source $(\mathrm{K} \alpha 1486.58 \mathrm{eV})$ with a spot size of $1 \mathrm{~mm}$. The source power was $150 \mathrm{~W}$, the takeoff angle was set normal to the sample surface, the construction and peak fitting in the narrow region spectra was performed using a Shirley type background, and the synthetic peaks were of a mixed Gaussian-Lorentzian type. Adventitious carbon was used for charge reference, and the $\mathrm{C} 1 \mathrm{~s}$ line of adventitious hydrocarbon was assumed to have a binding energy of $284.8 \mathrm{eV}$. The X-ray diffraction analyses were performed with a Philips X'Pert PRO MPD with a Cu X-ray source (Ko1 $1.5406 \AA$, $\mathrm{K} \alpha 21.5444 \AA, \mathrm{K} \beta 1.3922 \AA$, $\mathrm{K} \alpha 2 / \mathrm{K} \alpha 1=0.5)$. The measurements were carried out directly on the electrode surfaces modified with the deposited materials at an accelerating voltage of $40 \mathrm{kV}$ and a current of $40 \mathrm{~mA}$ in gonio mode $(\theta: \theta)$.

\section{RESULTS AND DISCUSSION}

a. Electrochemical Synthesis of Copper Hydroxysulfate Hierarchical Structures. The cation exchange properties of the $\mathrm{PPy}-\mathrm{PSS}$ films ${ }^{36-39}$ can be used to capture $\mathrm{Cu}^{2+}$ ions from aqueous copper solutions. In order to determine the potential at which the $\mathrm{Cu}^{2+}$ cations are captured, the mass of the polymer 


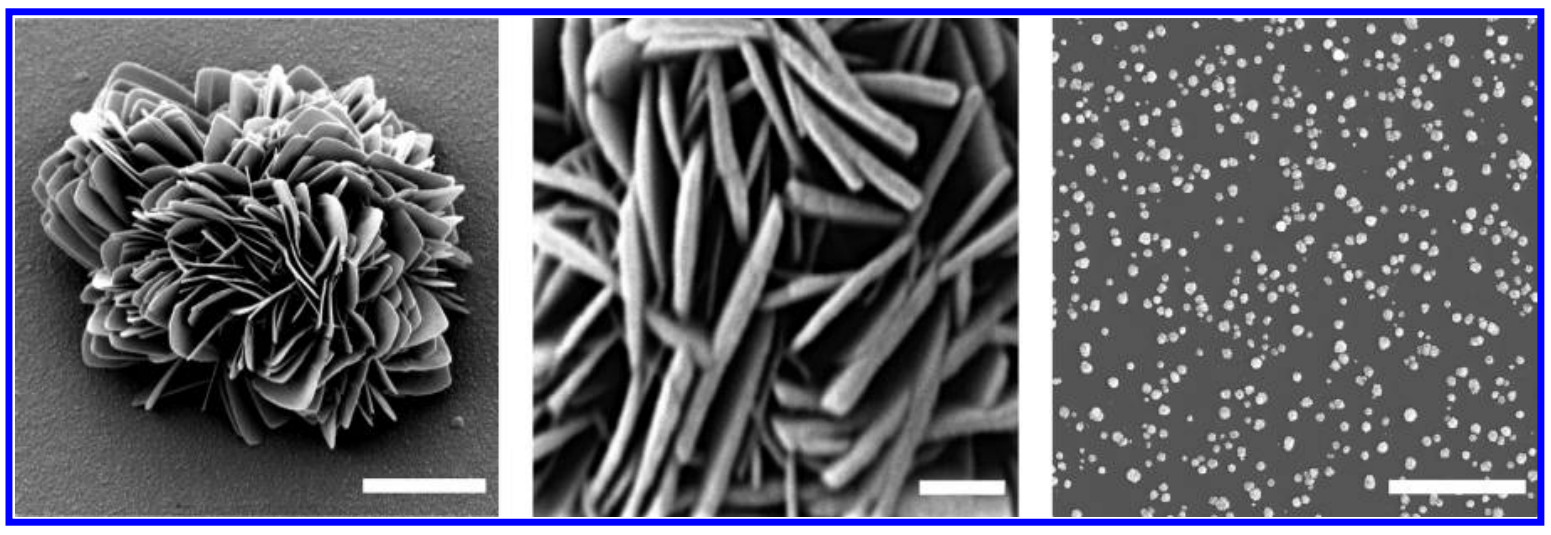

Figure 2. Hierarchical copper-based micro/nanostructures electrochemically deposited on PPy-PSS films in aerated or oxygen-saturated $0.10 \mathrm{M}$ $\mathrm{CuSO}_{4}$ at the constant potential of $0.10 \mathrm{~V}$ vs SCE. Overall structure (left, scale bare $5 \mu \mathrm{m}$ ), close-up of the nanosheets (center, scale bar $500 \mathrm{~nm}$ ), and surface distribution (right, scale bar $50 \mu \mathrm{m}$ ).

was monitored as a function of the applied potential. A potential sweep from 0.60 to $0.10 \mathrm{~V}$ vs SCE was applied to a PPy-PSS thin film immersed in a $0.10 \mathrm{M} \mathrm{CuSO}_{4}$ solution, and the change in mass of the film was measured. For comparative purposes, a similar experiment was performed in a $0.10 \mathrm{M} \mathrm{NaPSS}$ solution. It is seen from Figure 1 that the mass of the PPy-PSS film increases steadily during the sweep demonstrating that $\mathrm{Cu}^{2+}$ ions are incorporated into the PPy-PSS film. An increase in mass is also observed when the film is immersed in the NaPSS solution, confirming the capture of cations. In the latter case the mass increase is lower since $\mathrm{Na}^{+}$is lighter than $\mathrm{Cu}^{2+}$. However, whereas the mass change for $\mathrm{Na}^{+}$is substantially linear as a function of potential, for $\mathrm{Cu}^{2+}$ the mass increases more rapidly below $0.20 \mathrm{~V}$ vs SCE indicating that a significant deposition process occurs in this potential range.

In order to investigate this deposition process, SEM micrographs were recorded of the PPy-PSS film-modified electrodes after they were held at a potential of $0.10 \mathrm{~V}$ vs SCE in $0.10 \mathrm{M}$ $\mathrm{CuSO}_{4}$ solutions. The micrographs show the formation of copperbased hierarchical micro/nanostructures as given in Figure 2. These flowerlike structures are made of a large number of nanothin sheets organized in hemispherical clusters evenly distributed on the film surface. The thickness of the nanosheets ranges from 50 to $200 \mathrm{~nm}$, while the overall size of the clusters is about $5-10 \mu \mathrm{m}$. These structures are the first example of copper-based flowerlike structures electrochemically deposited on conducting polymers. In addition, they are made up from copper hydroxide and sulfate as discussed later. This finding is highly novel as hierarchical copper structures known to date are prepared hydrothermally in alkaline solutions and are usually made of copper oxides. ${ }^{10-12}$

The electrochemical deposition of the copper-based structures was reproducible and took less than $30 \mathrm{~min}$ as shown in Figure 3. After the first $10 \mathrm{~min}$, the reduction currents reach and fluctuate around a plateau value. Fluctuations of this kind are typical of two-dimensional progressive nucleation taking overlap into account $^{41}$ confirming that sheetlike deposits grow and overlap with each other at different rates.

b. Investigation of the Reduction Processes Occurring at the PPy-PSS Films. The reduction of $\mathrm{Cu}^{2+}$ ions at PPy-PSS thin films was examined by performing a very slow sweep of potential from 0.30 to $-0.40 \mathrm{~V}$ vs SCE at a scan rate of $0.1 \mathrm{mV} / \mathrm{s}$ in $0.10 \mathrm{M} \mathrm{CuSO}_{4}$. As shown in Figure 4, the wave corresponding to the reduction of $\mathrm{Cu}^{2+}$ ions to copper metal is recorded at potentials lower than $0.10 \mathrm{~V}$ vs SCE, in agreement with the

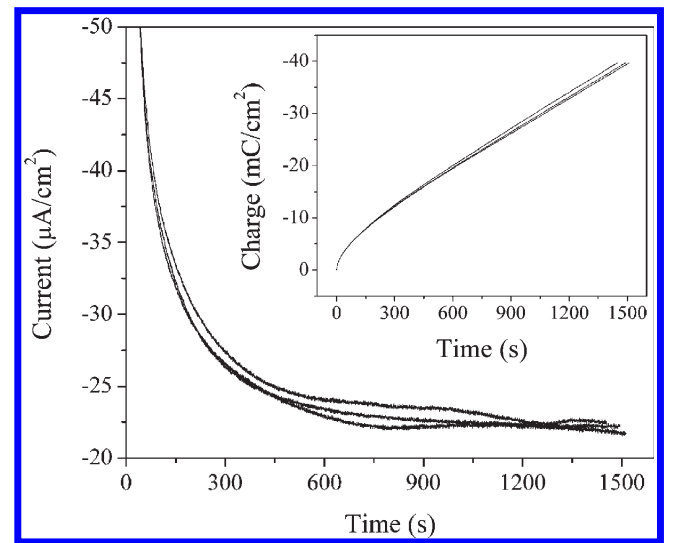

Figure 3. Current- and charge-time plots recorded during the deposition of hierarchical copper-based micro/nanostructures at PPy-PSS films in aerated $0.10 \mathrm{M} \mathrm{CuSO}_{4}$ at $0.10 \mathrm{~V}$ vs SCE on glassy carbon electrodes.

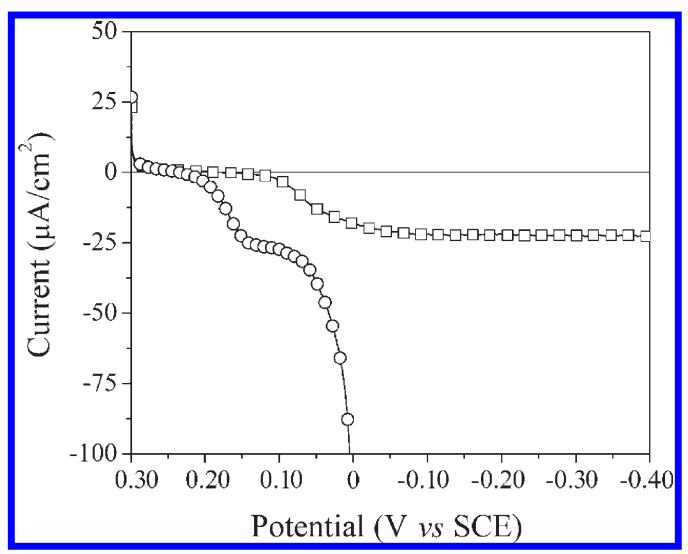

Figure 4. Current-potential plots recorded at $\mathrm{PPy}-\mathrm{PSS}$ films in aerated $0.10 \mathrm{M} \mathrm{CuSO}_{4}\left(-\mathrm{O}_{-}\right)$and in aerated $0.10 \mathrm{M} \mathrm{ZnSO}$ $(-\square-)$ upon applying a reduction potential sweep at $0.1 \mathrm{mV} / \mathrm{s}$ on glassy carbon electrodes.

standard reduction potential of $\mathrm{Cu}^{2+}$ ions to copper metal, 0.099 $\mathrm{V}$ vs SCE. For comparison, the same reduction sweep in $0.10 \mathrm{M}$ $\mathrm{ZnSO}_{4}$ was characterized by a current plateau. In the case of $\mathrm{Zn}^{2+}$ the standard reduction potential, $-1.003 \mathrm{~V}$ vs SCE, is 


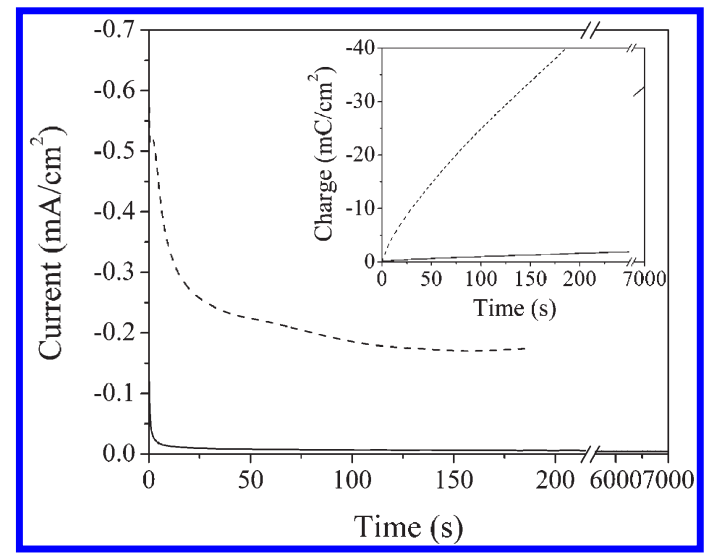

Figure 5. Current - and charge-time plots recorded at $0.10 \mathrm{~V}$ vs SCE for the PPy-PSS films in nitrogen- (-) and oxygen- $(---)$ saturated $0.10 \mathrm{M} \mathrm{CuSO}_{4}$ solutions on glassy carbon electrodes.

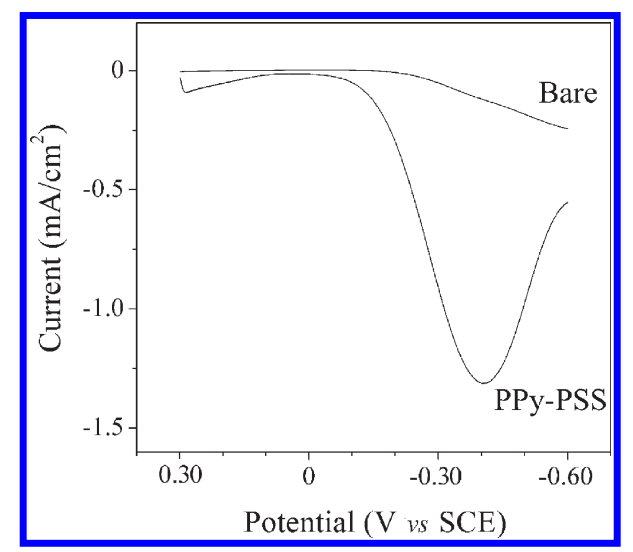

Figure 6. Net current associated with the reduction of oxygen at bare and $\mathrm{PPy}-\mathrm{PSS}$-modified rotating disk glassy carbon electrodes in $0.10 \mathrm{M}$ $\mathrm{Na}_{2} \mathrm{SO}_{4}$ at $10 \mathrm{mV} / \mathrm{s}$ and $2000 \mathrm{rpm}$.

much lower than that of copper, and the current plateau must be related to a different process than the reduction to zinc metal. Accordingly, the current plateau between 0.20 and $0.10 \mathrm{~V}$ vs SCE in the case of the copper system is related to another process that occurs in addition to the capture and reduction of the $\mathrm{Cu}^{2+}$ ions.

The process occurring at the plateau currents was determined to be the electrocrystallization of the hydroxysulfate-based materials. In fact, such a process was observed with either the copper or zinc ions following the reduction of dissolved oxygen to form hydroxide ions. Dissolved oxygen is a key reactant for the deposition of the copper-based structures, as without it the electrodeposition does not occur. This is shown clearly from the data presented in Figure 5 where current-time and chargetime plots of deposition are compared in nitrogen- and oxygensaturated solutions. In the absence of oxygen, the current drops immediately to very low values and no deposit is formed at the film even after $7000 \mathrm{~s}$. On the other hand, in the oxygen-saturated solution, the deposition current is much higher than that recorded in an aerated solution and hierarchical structures are formed at a higher rate. The deposition in the presence of oxygen is approximately 10 times faster, in comparison to the aerated solutions (Figures 3 and 5).

It appears that dissolved oxygen is reduced at the PPy-PSS film to form hydroxide ions. This causes an increase in the local

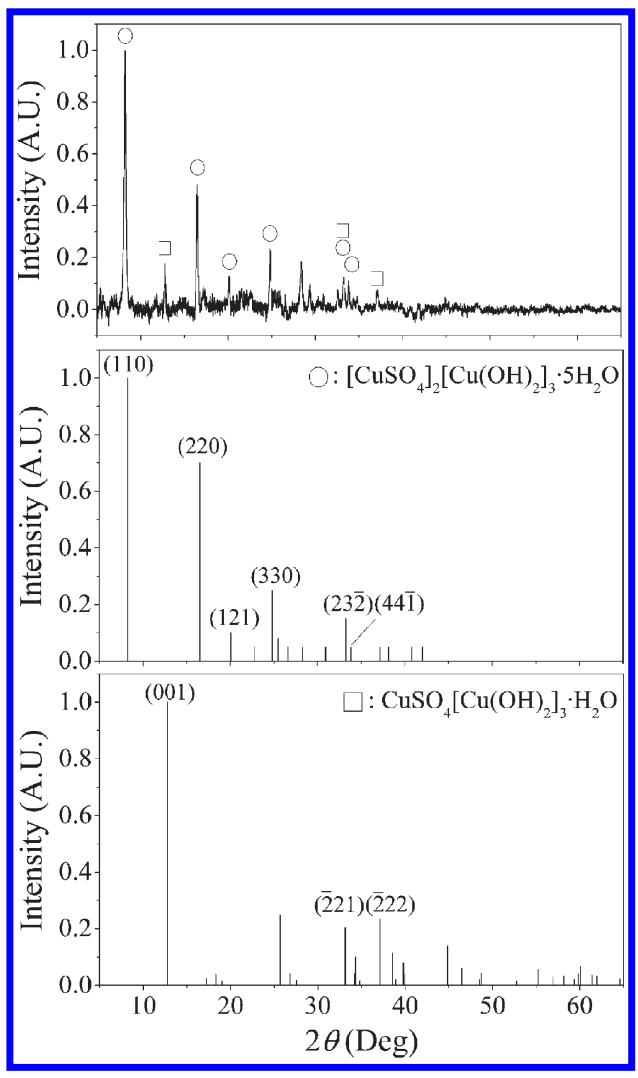

Figure 7. XRD peak assignment for the hierarchical copper-based micro/nanostructures prepared at $\mathrm{PPy}-\mathrm{PSS}$ films in oxygen-saturated $0.10 \mathrm{M} \mathrm{CuSO}_{4}$ at $0.10 \mathrm{~V}$ vs SCE on a glassy carbon electrode. The diffraction peaks are identified as those of copper sulfate hydroxide hydrate, $\mathrm{O}\left[\mathrm{CuSO}_{4}\right]_{2}\left[\mathrm{Cu}(\mathrm{OH})_{2}\right]_{3} \cdot 5 \mathrm{H}_{2} \mathrm{O}$, and posnjakite, $\mathrm{CuSO}_{4}\left[\mathrm{Cu}(\mathrm{OH})_{2}\right]_{3} \cdot \mathrm{H}_{2} \mathrm{O}$.

$\mathrm{pH}$ at the PPy-PSS interface which facilitates the electrocrystallization of the hierarchical micro/nanostructures. To support this explanation, the oxygen reduction reaction (ORR) at the PPy-PSS-modified electrodes was examined using a rotating disk electrode. The bare and film-modified electrodes were scanned over the same potential range with the electrode spinning at $2000 \mathrm{rpm}$. The net currents of reduction were calculated by subtracting the current measured in nitrogen- from the one measured in the oxygen-saturated solutions (Figure 6). The highest net current was registered at the film-modified electrodes showing the enhanced effect of the film on the ORR. The reduction of oxygen at these potentials is not surprising considering the positive value of its standard redox potential; however, it is well-known that the ORR is very slow and thus requires large overpotentials. ${ }^{42}$

The shape of the curves in Figure 6 is informative of the nature of the reduction processes. It is evident that none of the curves have the typical sigmoidal shape characteristic of the steady-state mass transport condition. The reduction process at the bare electrode is probably slow, and a plateau current is not reached. Instead, the peak current at the film-modified electrode might be due to the limited diffusion of oxygen in the polymer film. Since the actual ORR is taking place at the electrode/polymer interface, ${ }^{43,44}$ the current starts dropping after the depletion of oxygen present in the film. It is likely that the diffusion of oxygen through the film is too slow to sustain the current flow. However, 
the ORR at the modified electrodes is clearly enhanced when compared to the bare electrode.

c. Characterization of the Copper-Based Hierarchical Structures. i. XRD Measurements. In order to identify the crystalline components of the copper-based structures, the XRD patterns of the bare and copper-modified electrodes were analyzed and compared as described in the Supporting Information. The resulting XRD pattern for the hierarchical

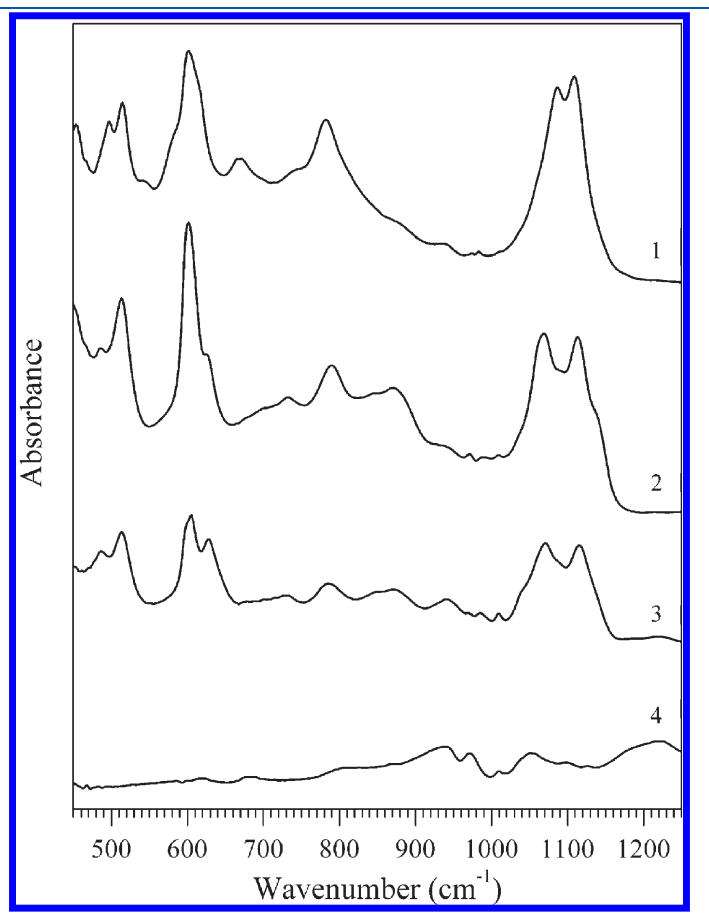

Figure 8. ATR-IR spectra of the hierarchical copper-based micro/ nanostructures deposited onto PPy-PSS thin films in the wavenumber region of the sulfate vibrational modes. The spectra are related to copper-based micro/nanostructures that were freshly deposited (1) and reduced at $-0.70 \mathrm{~V}$ vs $S C E(2)$ or $-1.50 \mathrm{~V}$ vs SCE (3) for $15 \mathrm{~min}$. The spectrum of $\mathrm{PPy}-\mathrm{PSS}$ is also shown (4). copper-based micro/nanostructures and the corresponding assignment of the peaks are reported in Figure 7. The majority of the peaks are related to the presence of copper sulfate hydroxide hydrate, $\left[\mathrm{CuSO}_{4}\right]_{2}\left[\mathrm{Cu}(\mathrm{OH})_{2}\right]_{3} \cdot 5 \mathrm{H}_{2} \mathrm{O}$ (ICDD PDF 00-041-0007). An additional crystalline phase is identified as posnjakite, $\mathrm{CuSO}_{4}[\mathrm{Cu}-$ $\left.(\mathrm{OH})_{2}\right]_{3} \cdot \mathrm{H}_{2} \mathrm{O}$ (ICDD PDF 00-043-0670). The identification of these two compounds is in agreement with the data obtained from ATR-IR and XPS experiments as discussed in the next sections.

ii. ATR-IR Studies. The ATR-IR spectra were recorded for both freshly deposited and electrochemically reduced micro/nanostructures from 450 to $4000 \mathrm{~cm}^{-1}$. The main absorption bands of both the pristine and reduced micro/nanostructures are located in two characteristic regions from 450 to $1250 \mathrm{~cm}^{-1}$ and from 2800 to $3800 \mathrm{~cm}^{-1}$. Reliable IR data of copper hydroxysulfate compounds could only be obtained from the literature for antlerite and brochantite. ${ }^{4-47}$ Proposed assignments for the bands observed in the ATR-IR spectra recorded for the copperbased hierarchical structures in the region of $450-1250 \mathrm{~cm}^{-1}$ are given in Table 1.

The ATR-IR spectra of the copper-based micro/nanostructures in the range $450-1250 \mathrm{~cm}^{-1}$ are shown in Figure 8 . The first feature common to all spectra is the band at $1000-1200 \mathrm{~cm}^{-1}$ characterized by a splitting. This band is assigned to the fundamental vibrational mode $v_{3}$, and the splitting of this band is due to the bound state of sulfate in the crystalline structure of the material as has been proposed for this type of structure in the literature. ${ }^{45,46}$ Another fundamental vibrational mode of $\mathrm{SO}_{4}$ is the $v_{4}$ which is observed for the free sulfate ion at $613 \mathrm{~cm}^{-1}$. 45 A splitting of the band related to this mode is observed in the spectra of antlerite and brochantite with three and two main peaks, respectively. ${ }^{45,46}$ In the case of the micro/nanostructures, the band splitting is only obtained after reduction at $-1.50 \mathrm{~V}$ vs $\mathrm{SCE}$, with the corresponding peaks appearing at 604 and $628 \mathrm{~cm}^{-1}$ (Table 1).

The other two fundamental vibrational modes of $\mathrm{SO}_{4}$ are the $v_{1}$ and $v_{2}$. In the case of the $v_{1}$ mode, the associated band for each of the hierarchical structures is significantly lower in intensity than the analogous band in the spectrum of either antlerite or

Table 1. Positions of the ATR-IR Peaks of the Hierarchical Copper-Based Micro/Nanostructures Related to the Fundamental Vibrational Modes of $\mathrm{SO}_{4}{ }^{*}$

\begin{tabular}{|c|c|c|c|c|c|}
\hline \multirow[b]{3}{*}{ assignment } & \multicolumn{5}{|c|}{ wavenumber $\left(\mathrm{cm}^{-1}\right)$} \\
\hline & \multirow[b]{2}{*}{$\mathrm{CuSO}_{4}\left[\mathrm{Cu}(\mathrm{OH})_{2}\right]_{2}$ antlerite } & \multirow[b]{2}{*}{$\mathrm{CuSO}_{4}\left[\mathrm{Cu}(\mathrm{OH})_{2}\right]_{3}$ brochantite } & \multicolumn{3}{|c|}{$\mathrm{Cu}$ hierarchical } \\
\hline & & & pristine & $-0.70 \mathrm{~V} / 15 \mathrm{~min}$ & $-1.50 \mathrm{~V} / 15 \mathrm{~min}$ \\
\hline \multirow[t]{3}{*}{$v_{3}\left(\mathrm{SO}_{4}\right)$} & $1155(\mathrm{~s})$ & - & - & $1141(\mathrm{sh})$ & - \\
\hline & $1100(\mathrm{~s})$ & $1120(\mathrm{~s})$ & $1109(\mathrm{~s})$ & $1113(\mathrm{~s})$ & $1115(\mathrm{~s})$ \\
\hline & $1080(\mathrm{~s})$ & $1085(\mathrm{~s})$ & $1087(\mathrm{~s})$ & $1070(\mathrm{~s})$ & $1071(\mathrm{~s})$ \\
\hline$v_{1}\left(\mathrm{SO}_{4}\right)$ & $990(\mathrm{~s})$ & $980(\mathrm{~m})$ & $983(\mathrm{vw})$ & $988(\mathrm{vw})$ & $985(\mathrm{w})$ \\
\hline \multirow[t]{3}{*}{$v_{4}\left(\mathrm{SO}_{4}\right)$} & $670(\mathrm{~m})$ & - & $669(\mathrm{~m})$ & - & - \\
\hline & $640(\mathrm{~s})$ & $625(\mathrm{~s})$ & $617(\mathrm{sh})$ & $625(w)$ & $628(\mathrm{~s})$ \\
\hline & $610(\mathrm{~s})$ & $600(\mathrm{~s})$ & $601(s)$ & $601(\mathrm{~s})$ & $604(\mathrm{~s})$ \\
\hline \multirow[t]{3}{*}{$v_{2}\left(\mathrm{SO}_{4}\right)$} & $518(\mathrm{~m})$ & $513(\mathrm{~m})$ & $515(\mathrm{~m})$ & $514(\mathrm{~m})$ & $515(\mathrm{~m})$ \\
\hline & $488(\mathrm{~m})$ & $484(\mathrm{~s})$ & $497(\mathrm{~m})$ & $486(w)$ & $487(\mathrm{~m})$ \\
\hline & $457(\mathrm{~m})$ & $462(\mathrm{~m})$ & $453(\mathrm{~m})$ & $-(\mathrm{a})$ & $-(\mathrm{a})$ \\
\hline
\end{tabular}

${ }^{*}$ The assignment of the peaks is given with respect to the spectra of antlerite and brochantite as reported by Ramamurthy and Secco. ${ }^{45,46}$ The intensity of the peaks is given beside their wavenumbers ( $\mathrm{s}=$ strong; $\mathrm{m}=$ medium; $\mathrm{w}=$ weak; $\mathrm{vw}=$ very weak; $\mathrm{sh}$ = shoulder; $\mathrm{a}=$ band shifted to below the spectral window of $450 \mathrm{~cm}^{-1}$ ). 


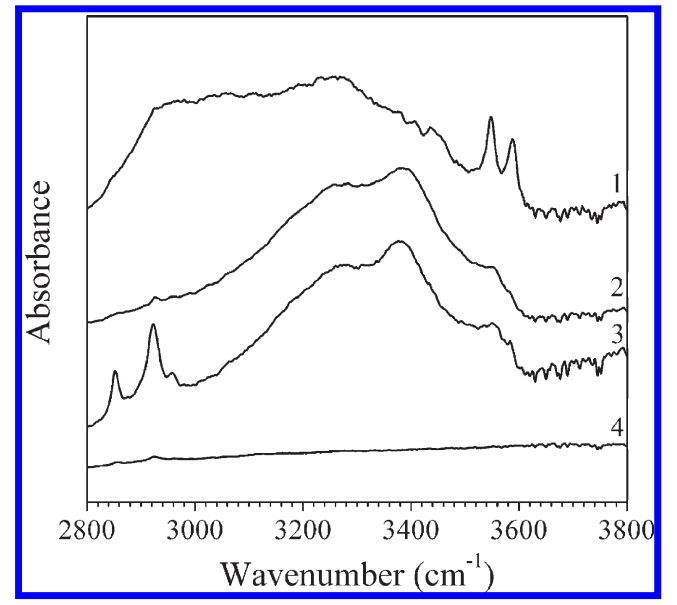

Figure 9. ATR-IR spectra of the hierarchical copper-based micro/ nanostructures in the wavenumber range of hydroxide vibrational modes. The spectra correspond to structures that were freshly deposited (1) and reduced at $-0.70 \mathrm{~V}$ vs SCE (2) or at $-1.50 \mathrm{~V}$ vs SCE (3) for 15 min in $0.10 \mathrm{M} \mathrm{Na}_{2} \mathrm{SO}_{4}$. The spectrum of PPy-PSS is also shown (4).

brochantite. The three peaks at 453,497 , and $515 \mathrm{~cm}^{-1}$ are assigned to the $v_{2}$ mode by comparison of the spectrum of the pristine hierarchical structures with those of brochantite and antlerite (Table 1).

The ATR-IR spectra of the copper-based micro/nanostructures in the range $2800-3800 \mathrm{~cm}^{-1}$ are enlarged in Figure 9. In this range there are two main features, a broad band with two wide maxima at about 3260 and $3380 \mathrm{~cm}^{-1}$ and two well-resolved peaks above $3500 \mathrm{~cm}^{-1}$. These features are related to three different kinds of $\mathrm{OH}$ groups present in the copper-based deposits. The two wide maxima are assigned to $\mathrm{OH}$ groups with a medium and a high degree of hydrogen bonding, respectively, while the two narrow peaks are related to free non-hydrogen-bonded $\mathrm{OH}$ groups. ${ }^{45,46}$ In the case of the freshly deposited copper-based structures the broad band is almost flat, whereas the two peaks related to the free $\mathrm{OH}$ are easily distinguishable above the background. The relative intensity of the two features is reversed after reduction. The broad band is now better defined with two discernible maxima, while the two resolved peaks are hardly noticeable. It follows that the reduction treatment causes a transition from free to bound $\mathrm{OH}$ groups at both -0.70 and $-1.50 \mathrm{~V}$ vs SCE. These three classes of $\mathrm{OH}$ groups are observed in the spectra of both antlerite and brochantite. ${ }^{45}$ In summary, the ATR-IR data recorded for the structures before and after reduction have the characteristic features of the $\mathrm{OH}$ groups of the copper hydroxysulfate compounds.

Interestingly, the bands observed in the spectra recorded upon reduction of the copper-based structures (Table 1) have a very good correlation with those of brochantite. As stated above the composition of the structures was determined from XRD data to be copper sulfate hydroxide hydrate and posnjakite. The IR spectrum of posnjakite would be expected to be very similar to that of brochantite as they differ in chemical composition only by one water molecule. Therefore, this would suggest that the changes in the spectra recorded upon reduction occur because the copper sulfate hydroxide hydrate $\left(\left[\mathrm{CuSO}_{4}\right]_{2}\left[\mathrm{Cu}(\mathrm{OH})_{2}\right]_{3} \cdot 5 \mathrm{H}_{2} \mathrm{O}\right)$ in the pristine structures is possibly converted to brochantite $\left(\mathrm{CuSO}_{4}\left[\mathrm{Cu}(\mathrm{OH})_{2}\right]_{3}\right)$ and/or posnjakite $\left(\mathrm{CuSO}_{4}\left[\mathrm{Cu}(\mathrm{OH})_{2}\right]_{3} \cdot \mathrm{H}_{2} \mathrm{O}\right)$. This conversion occurs as more $\mathrm{OH}^{-}$ions are formed at the polymer surface from the reduction of dissolved oxygen at lower potentials. iii. XPS Studies. A PPy-PSS film modified with copper-based structures was reduced at $-1.00 \mathrm{~V}$ vs SCE for $5 \mathrm{~min}$ in $0.10 \mathrm{M}$ $\mathrm{Na}_{2} \mathrm{SO}_{4}$ prior to the analysis in order to evaluate the effect of a mild reduction treatment. The XPS survey and narrow range spectra of the modified films with the deconvolution of the peaks are given in Figure 10.

Five chemical elements are identified in the survey spectra, namely, $\mathrm{Cu}, \mathrm{S}, \mathrm{O}, \mathrm{C}$, and $\mathrm{N}$. The first three were also identified using EDX (not shown here) and are the component elements of the copper-based micro/nanostructures. The other two, $\mathrm{C}$ and $\mathrm{N}$, are due to the $\mathrm{PPy}-\mathrm{PSS}$ film since the area of analysis $(1 \mathrm{~mm} \times$ $1 \mathrm{~mm}$ ) was large enough to probe both the structures and the surrounding polymer film.

The narrow range spectrum of the copper signal $\left(\mathrm{Cu} 2 \mathrm{p}_{3 / 2}\right)$ shows three different peaks at 935.0, 937.1, and $943.8 \mathrm{eV}$ (Figure 10). Two other peaks are found at 933.2 and $940.8 \mathrm{eV}$ from the deconvolution of the signal. The peak at $935.0 \mathrm{eV}$ is related to the presence of $\mathrm{Cu}(\mathrm{II})$, whereas the small peak at $933.2 \mathrm{eV}$ is indicative of $\mathrm{Cu}(\mathrm{I})$ and/or $\mathrm{Cu}(\mathrm{II}) .^{48,49}$ Upon consideration of the literature, the peak at $937.1 \mathrm{eV}$ could possibly be related to the presence of an octahedrally oxygen-coordinated $\mathrm{Cu}$ (II) species. ${ }^{50}$ The peaks at 940.8 and $943.8 \mathrm{eV}$ are satellites of the parent peak at $935.0 \mathrm{eV}$ and are due to the shakeup effects typically observed for $\mathrm{Cu}$ (II) oxide, sulfates, and hydroxysulfates. ${ }^{49}$ According to the literature, ${ }^{48}$ the parent peak of copper oxide is found at about $933.8 \mathrm{eV}$, while that of copper sulfate is observed at about $934.9 \mathrm{eV} .^{51,52}$ It follows that the present peak is more likely to be related to sulfate rather than to oxide species.

The XPS spectrum of the sulfur signal (S 2p) has two separate peaks at 168.3 and $170.2 \mathrm{eV}$ (Figure 10). The fitting of the signal with two doublets allows the identification of two other peaks at 169.5 and $171.4 \mathrm{eV}$, respectively. Each couple of peaks is a doublet $S$ $2 \mathrm{p}_{3 / 2,1 / 2}$ with a $2: 1$ intensity ratio and a $1.2 \mathrm{eV}$ splitting due to spin-orbit coupling in the sulfur atoms. The doublet at 168.3 and $169.5 \mathrm{eV}$ is due to the sulfonate groups of the PPy-PSS film, ${ }^{53}$ whereas the doublet at 170.2 and $171.4 \mathrm{eV}$ is due to the sulfate ions of the copper-based micro/nanostructures. ${ }^{54,55}$

The oxygen signal ( $\mathrm{O} 1 \mathrm{~s})$ in the XPS spectrum shows two separate peaks at 531.6 and $533.8 \mathrm{eV}$ (Figure 10). A third peak at $535.3 \mathrm{eV}$ is found from the deconvolution of the signal. According to the literature, ${ }^{56,57}$ the first peak at $531.6 \mathrm{eV}$ can be assigned to the sulfonate oxygen of the dopant present in the polymer film, while the other two peaks are due to the oxygen contribution of sulfate ions, water, and polymer-oxidized moieties.

The narrow range spectrum of the carbon signal (C 1s) shows two separate peaks at 284.8 and $286.9 \mathrm{eV}$ and a tail at higher binding energy (Figure 10). The deconvolution of the signal allows the identification of three other peaks underneath the tail at 287.6, 288.7, and $290.4 \mathrm{eV}$, respectively. According to the literature, ${ }^{57}$ the peaks can be assigned as follows. The peak at $284.8 \mathrm{eV}$ is related to the $\alpha$ - and $\beta$-carbons of the PPy rings along with the aromatic carbons of PSS and adventitious carbon. The dominant peaks at 286.9 and $287.6 \mathrm{eV}$ are given by several contributions, namely, the imine-like $(\mathrm{C}=\mathrm{N})$, polaron $\left(=\mathrm{C}-\mathrm{NH}^{\bullet+}\right)$, and hydroxylated defects $(\mathrm{C}-\mathrm{OH})$ of PPy. Instead, the peak at $288.7 \mathrm{eV}$ is attributed to the bipolarons $\left(-\mathrm{C}=\mathrm{N}^{+}\right)$ and carbonylic defects $(\mathrm{C}=\mathrm{O})$ of PPy. The last peak at $290.4 \mathrm{eV}$ is a shakeup satellite of the peak at $284.8 \mathrm{eV}$ and is caused by the $\pi-\pi^{*}$ electronic excitation of PPy. Significantly, the dominant peak at $286.9 \mathrm{eV}$ is indicative of the large number of imine-like functions present in the polymer film, as supported by the analysis of the nitrogen signal reported below. These functions are generated 


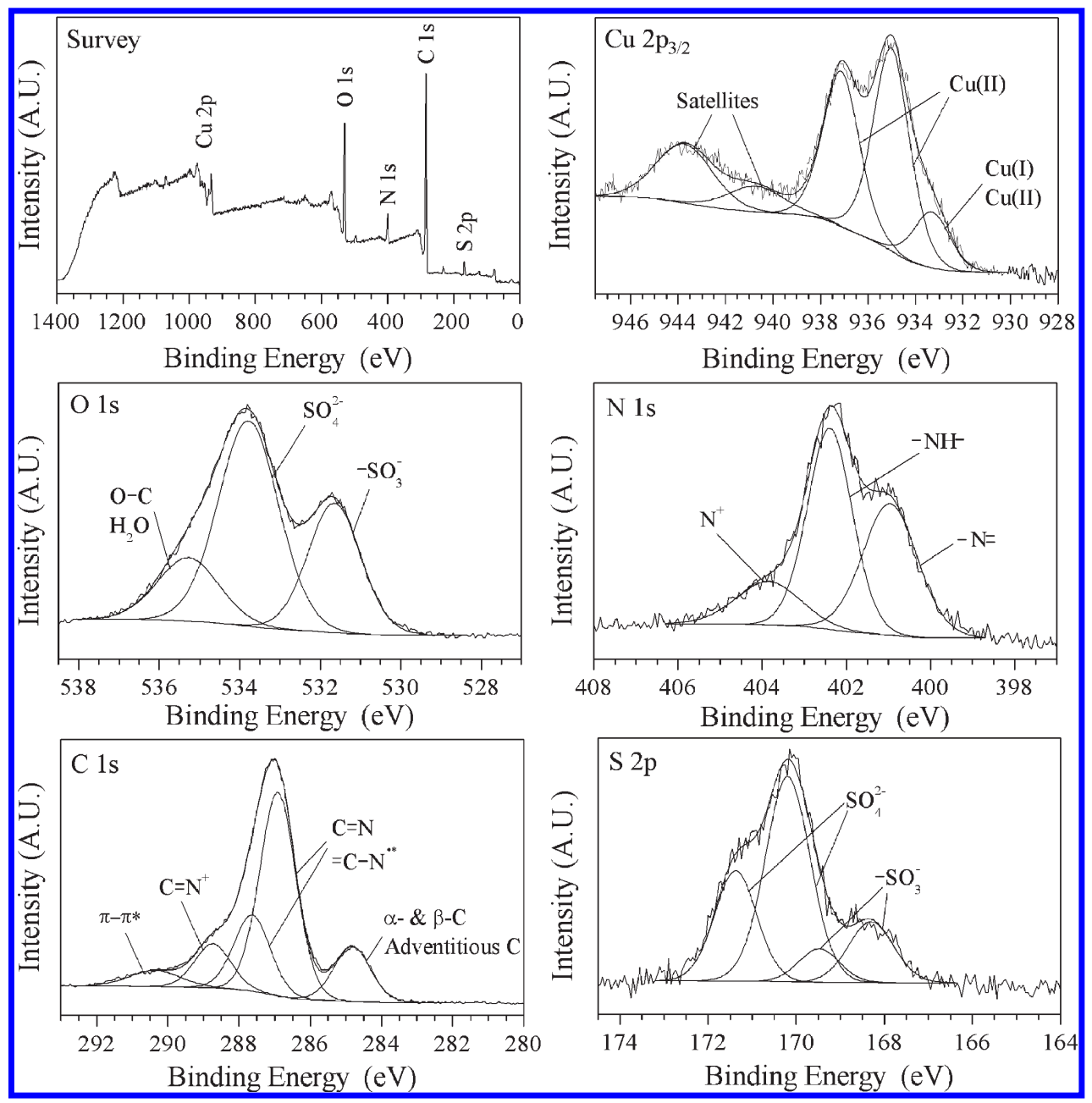

Figure 10. XPS spectra of the hierarchical copper-based micro / nanostructures formed at the PPy-PSS films in aerated $0.10 \mathrm{M} \mathrm{CuSO}_{4}$ at $0.10 \mathrm{~V}$ vs SCE. The copper-based structures were reduced at $-1.00 \mathrm{~V}$ vs SCE for $5 \mathrm{~min}$ in $0.10 \mathrm{M} \mathrm{Na}_{2} \mathrm{SO}_{4}$ prior to the analysis.

from the deprotonation of the pyrrolic nitrogen and are consistent with the presence of hydroxide ions in the polymer film from the reduction of dissolved oxygen.

The nitrogen signal (N 1s) in the XPS spectrum is composed of two peaks at 401.0 and $402.4 \mathrm{eV}$ and a tail at higher binding energy (Figure 10). The deconvolution of the signal allows the identification of another peak underneath the tail at $403.8 \mathrm{eV}$. According to the literature, ${ }^{58}$ the nitrogen signal of pristine PPy has three peaks at about 397.8, 399.7, and $400.5 \mathrm{eV}$. These peaks correspond to the deprotonated, neutral, and oxidized/protonated nitrogen, respectively. The present set of peaks is evidently shifted to higher binding energy compared to that of pristine PPy. However, a shift of the $\mathrm{N}$ 1s signal toward higher binding energy has been already observed in polypyrrole films modified with copper due to the interaction of copper ions with nitrogen. ${ }^{31,59}$

The last important aspect of the N 1s signal is the size of the peak at $401.0 \mathrm{eV}$ due to the imine-like nitrogen $(-\mathrm{N}=)$ which is strikingly large. This peak results from the deprotonation of the amine-like nitrogen $(-\mathrm{NH}-)$ during the deposition. It is shown in the literature ${ }^{68}$ that by treating PPy with $0.5 \mathrm{M} \mathrm{NaOH}$, the area of the imine-like nitrogen peak can become $50 \%$ of the overall area of the $\mathrm{N}$ 1s signal after the deprotonation of the pyrrolic nitrogen. In the present case the relative contribution of the deprotonated moieties is about $37 \%$, a value that can only be achieved by base

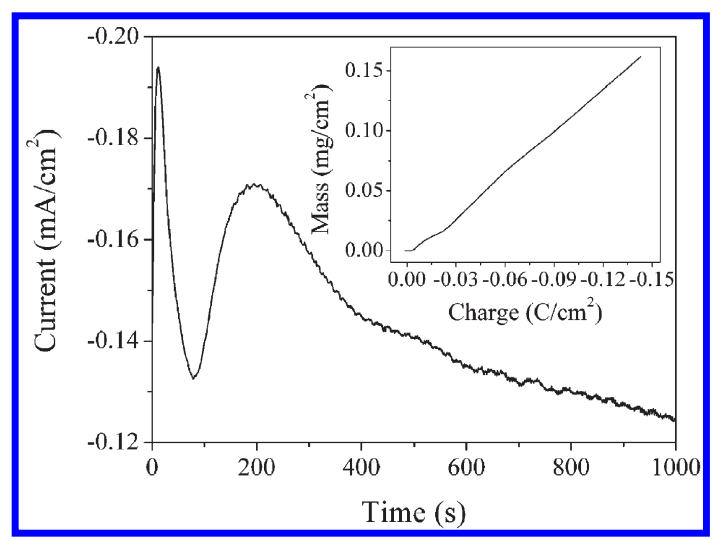

Figure 11. Current-time and mass-charge responses for the deposition of hierarchical copper-based micro/nanostructures at PPy-PSS films in oxygen-saturated $0.10 \mathrm{M} \mathrm{CuSO}_{4}$ solution at $0.10 \mathrm{~V}$ vs SCE on an AT-cut quartz crystal gold electrode.

treatment. Clearly, the deprotonation of the pyrrolic nitrogen is a consequence of the generation of hydroxide ions from the reduction of dissolved oxygen. This is supporting evidence that the local $\mathrm{pH}$ at the polymer film is much higher than in the bulk solution during the electrochemical deposition of the hierarchical structures. 


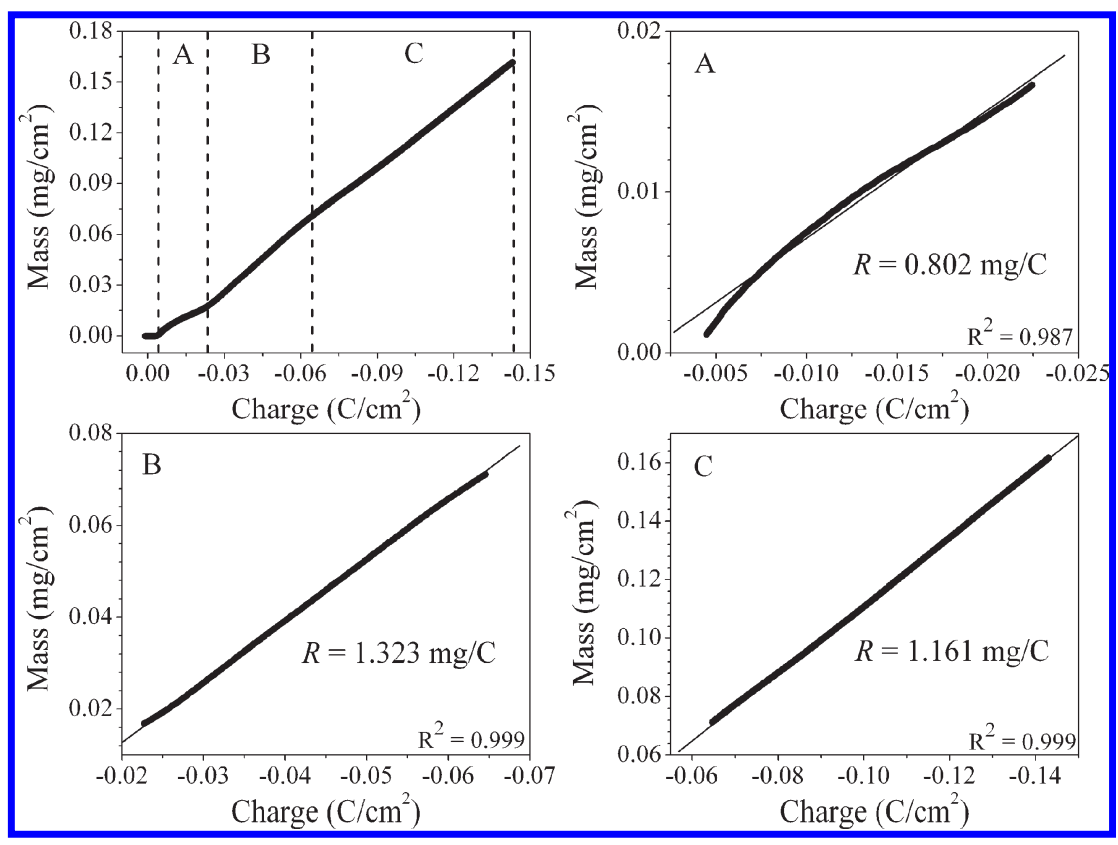

Figure 12. Linear regressions of the mass-charge curve for the deposition of hierarchical copper-based micro/nanostructures at PPy-PSS films in oxygen-saturated $0.10 \mathrm{M} \mathrm{CuSO}_{4}$ at $0.10 \mathrm{~V}$ vs SCE. The three segments, labeled in the first plot, are individually interpolated in the corresponding plots $\mathrm{A}, \mathrm{B}$, and $\mathrm{C}$. The absolute values of the slope (i.e., the mass-to-charge ratio $R$ ) and the correlation coefficient $\left(\mathrm{R}^{2}\right)$ of the regression lines are reported.

Table 2. Possible Reactions and Products for the Electrochemical Deposition of Hierarchical Copper-Based Micro/Nanostructures with Relative Values of Molar Mass $(M)$ and Mass-to-Charge Ratio $(R)$

\begin{tabular}{|c|c|c|}
\hline electrodeposition reactions and products & $M(\mathrm{~g} / \mathrm{mol})$ & $R(\mathrm{mg} / \mathrm{C})$ \\
\hline $3 \mathrm{Cu}^{2+}+\mathrm{O}_{2}+2 \mathrm{H}_{2} \mathrm{O}+\mathrm{SO}_{4}{ }^{2-}+4 \mathrm{e}^{-} \rightarrow \mathrm{CuSO}_{4}\left[\mathrm{Cu}(\mathrm{OH})_{2}\right]_{2}$ antlerite & 354.7 & 0.919 \\
\hline $4 \mathrm{Cu}^{2+}+1.5 \mathrm{O}_{2}+3 \mathrm{H}_{2} \mathrm{O}+\mathrm{SO}_{4}{ }^{2-}+6 \mathrm{e}^{-} \rightarrow \mathrm{CuSO}_{4}\left[\mathrm{Cu}(\mathrm{OH})_{2}\right]_{3}$ brochantite & 452.3 & 0.781 \\
\hline $4 \mathrm{Cu}^{2+}+1.5 \mathrm{O}_{2}+4 \mathrm{H}_{2} \mathrm{O}+\mathrm{SO}_{4}{ }^{2-}+6 \mathrm{e}^{-} \rightarrow \mathrm{CuSO}_{4}\left[\mathrm{Cu}(\mathrm{OH})_{2}\right]_{3} \cdot \mathrm{H}_{2} \mathrm{O}$ posnjakite & 470.3 & 0.812 \\
\hline $4 \mathrm{Cu}^{2+}+1.5 \mathrm{O}_{2}+5 \mathrm{H}_{2} \mathrm{O}+\mathrm{SO}_{4}{ }^{2-}+6 \mathrm{e}^{-} \rightarrow \mathrm{CuSO}_{4}\left[\mathrm{Cu}(\mathrm{OH})_{2}\right]_{3} \cdot 2 \mathrm{H}_{2} \mathrm{O}$ langite & 488.3 & 0.843 \\
\hline $5 \mathrm{Cu}^{2+}+1.5 \mathrm{O}_{2}+8 \mathrm{H}_{2} \mathrm{O}+2 \mathrm{SO}_{4}{ }^{2-}+6 \mathrm{e}^{-} \rightarrow\left[\mathrm{CuSO}_{4}\right]_{2}\left[\mathrm{Cu}(\mathrm{OH})_{2}\right]_{3} \cdot 5 \mathrm{H}_{2} \mathrm{O}$ copper sulfate hydroxide hydrate & 702.0 & 1.212 \\
\hline $2 \mathrm{Cu}^{2+}+0.5 \mathrm{O}_{2}+\mathrm{SO}_{4}{ }^{2-}+2 \mathrm{e}^{-} \rightarrow \mathrm{CuOCuSO}_{4}$ dolerophanite & 239.1 & 1.239 \\
\hline
\end{tabular}

iv. EQCM Measurements. The mass and charge of deposition of the hierarchical copper-based micro/nanostructures formed at PPy-PSS thin films in oxygen-saturated $0.10 \mathrm{M} \mathrm{CuSO}_{4}$ were monitored using an electrochemical quartz crystal microbalance (EQCM). The resulting responses are shown in Figure 11.

The current-time profile is typical of the electrochemical growth of overlapping nuclei. ${ }^{61}$ The mass-charge curve is characterized by three individual segments, as shown more clearly in Figure 12. A linear regression was performed on each segment in order to obtain the slopes of the mass-charge curve the absolute values of which correspond to the mass-to-charge ratios, $R$, of the deposited micro/nanostructures. These experimental ratios were then compared to those calculated for the different copper hydroxysulfate species that could be deposited on the films. The segments A, B, and C of the mass-charge curve are associated with three different stages of the copper-based micro/nanostructures deposition, namely, nucleation, nuclei overlapping, and multilayer growth. ${ }^{61}$ As shown in Figure 12, the value of $R$ changes during the deposition starting from 0.802 $\mathrm{mg} / \mathrm{C}$ for the nucleation, $1.323 \mathrm{mg} / \mathrm{C}$ for the nuclei overlapping, and finally $1.161 \mathrm{mg} / \mathrm{C}$ for the multilayer growth.

The experimental values of $R$ can be compared to the values calculated from a series of possible reduction reactions (Table 2). Antlerite
$\mathrm{CuSO}_{4}\left[\mathrm{Cu}(\mathrm{OH})_{2}\right]_{2}$, brochantite $\mathrm{CuSO}_{4}\left[\mathrm{Cu}(\mathrm{OH})_{2}\right]_{3}$, posnjakite $\mathrm{CuSO}_{4}\left[\mathrm{Cu}(\mathrm{OH})_{2}\right]_{3} \cdot \mathrm{H}_{2} \mathrm{O}$, langite $\mathrm{CuSO}_{4}\left[\mathrm{Cu}(\mathrm{OH})_{2}\right]_{3} \cdot 2 \mathrm{H}_{2} \mathrm{O}$, copper sulfate hydroxide hydrate $\left[\mathrm{CuSO}_{4}\right]_{2}\left[\mathrm{Cu}(\mathrm{OH})_{2}\right]_{3} \cdot 5 \mathrm{H}_{2} \mathrm{O}$, and dolerophanite $\mathrm{CuOCuSO}_{4}$ are possible copper sulfate species known from the literature. ${ }^{62,63}$ In the case of the nucleation stage, the slope of the mass-charge segment is $0.802 \mathrm{mg} / \mathrm{C}$ which is closely related to the deposition of hydrated forms of brochantite (e.g., posnjakite $\mathrm{CuSO}_{4}\left[\mathrm{Cu}(\mathrm{OH})_{2}\right]_{3} \cdot \mathrm{H}_{2} \mathrm{O}$ with $0.812 \mathrm{mg} / \mathrm{C}$ which was identified as being present in the hierarchical structures from the XRD data). However, this segment is not actually linear $\left(\mathrm{R}^{2}=0.987\right)$, suggesting the evolution of the deposition process toward a steady condition. Consequently, the slope of this segment is just an average of values of $R$ that change rapidly during the nucleation. The other two segments are effectively linear $\left(R^{2}=0.999\right)$, and their slopes are representative of steady deposition processes. The mass-to-charge ratios for these segments are 1.323 and $1.161 \mathrm{mg} / \mathrm{C}$. These values are close to the $R$ of dolerophanite, $1.239 \mathrm{mg} / \mathrm{C}$, or copper sulfate hydroxide hydrate, $1.212 \mathrm{mg} / \mathrm{C}$ (Table 1). The formation of dolerophanite, $\mathrm{CuOCuSO}_{4}$, is excluded because it reacts rapidly with water to yield pseudomorphs of antlerite. ${ }^{64}$ The formation of copper sulfate hydroxide hydrate, $\left[\mathrm{CuSO}_{4}\right]_{2}\left[\mathrm{Cu}(\mathrm{OH})_{2}\right]_{3} \cdot 5 \mathrm{H}_{2} \mathrm{O}$, is in excellent agreement with the XRD characterization of the hierarchical structures. It is possible that the partial formation of the posnjakite 


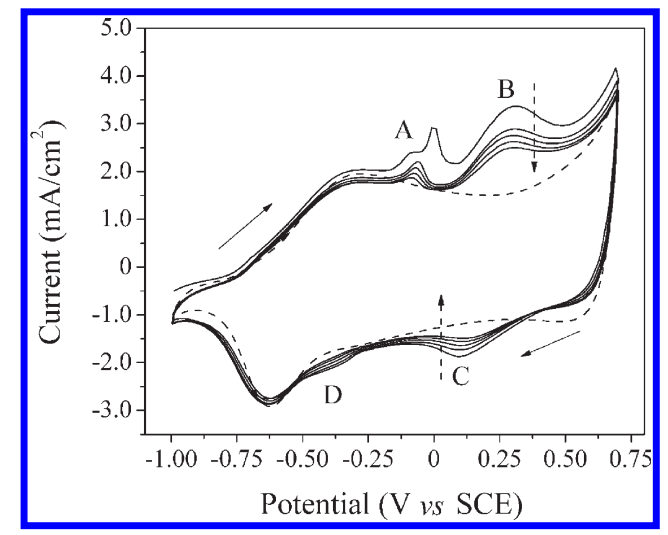

Figure 13. Cyclic voltammograms of a PPy-PSS film modified with hierarchical copper-based micro/nanostructures recorded at $100 \mathrm{mV} / \mathrm{s}$ in $0.10 \mathrm{M} \mathrm{Na}_{2} \mathrm{SO}_{4}$. The first five cycles of a copper-modified film (-) are compared to those of a pristine film $(---)$. The dotted arrows show the decrease in the peak current with increasing cycle number, while the solid arrows show the direction of the scan.

phase, $R=0.812 \mathrm{mg} / \mathrm{C}$, could explain the experimental value of $R$, $1.161 \mathrm{mg} / \mathrm{C}$, which is slightly lower than that of a pure copper sulfate hydroxide hydrate phase, $1.212 \mathrm{mg} / \mathrm{C}$.

v. CV studies. A PPy-PSS film modified with the copper-based structures was reduced at $-1.00 \mathrm{~V}$ vs SCE for $5 \mathrm{~min}$ in $0.10 \mathrm{M}$ $\mathrm{Na}_{2} \mathrm{SO}_{4}$ prior to the analysis. This short pretreatment was used to reduce the background current of the PPy-PSS film. A cyclic potential scan was then performed between -1.00 and $0.70 \mathrm{~V}$ vs SCE in the same solution. Representative data are shown in Figure 13.

In the resulting voltammograms, four peaks are evident, and these are labeled as A, B, C, and D (solid traces). The background electroactivity of the polymer was also considered by running the same scan on a pristine PPy-PSS film (dashed trace). The results obtained using ATR-IR spectroscopy indicate that the copper in the hierarchical structures does not undergo reduction in this potential range. Therefore, it is likely that the redox processes studied here arise from the copper ions captured in the polymer. The position of the XPS signal for nitrogen of the polymer was consistent with copper ions binding to the nitrogen of the PPy. The redox couples $\mathrm{A} / \mathrm{D}$ and $\mathrm{B} / \mathrm{C}$ are attributed to $\mathrm{Cu}(0) / \mathrm{Cu}(\mathrm{I})$ and $\mathrm{Cu}(\mathrm{I}) / \mathrm{Cu}(\mathrm{II})$ one-electron processes in accordance with work reported on related systems. ${ }^{6,30}$ The potential of peak A is slightly shifted $-100 \mathrm{mV}$ vs SCE compared to that reported by Cioffi et al., ${ }^{6}$ and peak D appears also at more negative potentials. However, the position of this latter peak is dependent on the film thickness. ${ }^{6}$ The splitting of peak A during the first scan is likely to be due to the presence of two different forms of adsorbed $\mathrm{Cu}(0)$ corresponding to two slightly shifted oxidation potentials. In general, all peaks fade with increasing cycle number due to the progressive dissolution of the deposited copper. Of particular interest is the first cycle which is recorded after reduction at $-1.00 \mathrm{~V}$ vs SCE. In this case, peak A corresponds to the conversion of $\mathrm{Cu}(0)$ to $\mathrm{Cu}(\mathrm{I})$ and assuming that only the $\mathrm{Cu}(\mathrm{I})$ generated through this process is available for conversion to $\mathrm{Cu}(\mathrm{II})$, then the peak heights of $\mathrm{A}$ and $\mathrm{B}$ should be similar. The fact that this is not the case suggests that $\mathrm{Cu}(\mathrm{I})$ is already present, and this now accounts for the higher peak currents recorded for peak B. During the reverse sweep, it appears that not all the $\mathrm{Cu}(\mathrm{I})$ generated at peak $\mathrm{C}$ is converted to $\mathrm{Cu}(0)$ at peak $\mathrm{D}$. This gives rise to $\mathrm{Cu}(\mathrm{I})$ which is converted to
$\mathrm{Cu}$ (II) during the subsequent forward cycle and is consistent with the higher peak currents observed for peak B during repetitive cycling. Given that the micro/nanostructures are mainly composed of copper(II) hydroxysulfates even after reduction at $-1.50 \mathrm{~V}$ vs $\mathrm{SCE}$ for $15 \mathrm{~min}$ as shown by the ATR-IR spectra presented earlier, it follows that the $\mathrm{Cu}(\mathrm{I})$ is likely to be formed and stabilized in the polymer film from the reduction of the $\mathrm{Cu}(\mathrm{II})$ ions captured during the electrodeposition process. The XPS data indicate that part of the copper is present in the $\mathrm{Cu}(\mathrm{I})$ state on the film after a reduction treatment at $-1.00 \mathrm{~V}$ vs SCE for $5 \mathrm{~min}$.

\section{CONCLUSIONS}

The electrochemical deposition of the copper-based micro/ nanostructure was performed at the surface of polypyrrolepolystyrene sulfonate (PPy-PSS) thin films. The electrochemistry of the film is a key factor in the overall deposition of the micro/nanostructures. These PPy-PSS films enable the capture of copper ions from the electrodeposition solution and facilitate the reduction of dissolved oxygen to hydroxide ions. The combination of the $\mathrm{Cu}^{2+}$ ions captured by the film, the $\mathrm{OH}^{-}$ ions generated from the reduction of the dissolved oxygen, and the $\mathrm{SO}_{4}{ }^{2-}$ ions of the electrolyte solution causes the deposition of the micro/nanostructures. This is essential for the electrocrystallization of the copper hydroxysulfates. The structures are made of copper sulfate hydroxide hydrate, $\left[\mathrm{CuSO}_{4}\right]_{2}$ $\left[\mathrm{Cu}(\mathrm{OH})_{2}\right]_{3} \cdot 5 \mathrm{H}_{2} \mathrm{O}$, and posnjakite, $\mathrm{CuSO}_{4}\left[\mathrm{Cu}(\mathrm{OH})_{2}\right]_{3} \cdot \mathrm{H}_{2} \mathrm{O}$. The elemental composition was deduced using XPS, the presence of sulfate and hydroxide ions was confirmed using ATR-IR and XPS, and the exact chemical structures were identified using $\mathrm{XRD}$. The EQCM and CV analysis are also in agreement with the electrodeposition of this mixture. The exploitation of the PPy-PSS film properties for the controlled electroprecipitation of hierarchical micro/nanostructures is novel and represents a new synthetic route to prepare materials that are usually formed using hydrothermal methods.

\section{ASSOCIATED CONTENT}

S Supporting Information. Analysis of the XRD raw data of the bare and copper-modified glassy carbon electrodes. This material is available free of charge via the Internet at http://pubs.acs.org.

\section{AUTHOR INFORMATION}

\section{Corresponding Author}

*E-mail chemistry.department@nuim.ie; tel. +353-1-7083770; fax: $+353-1-7083815$.

\section{ACKNOWLEDGMENT}

We thank Dr. Mircea Mondreanu, at the Tyndall National Institute, University College Cork, for the ATR-IR analyses, and Dr. Fathima Laffir and Dr. Serguei Belochapkine, at the Materials and Surface Science Institute, University of Limerick, for the XPS analyses. This work was supported by the Environmental Protection Agency Ireland as part of the Science, Technology, Research and Innovation for the Environment Programme financed by the Irish Government. Additional funding was provided by the Science Foundation Ireland through the National Access Programme of the Tyndall National Institute, University College Cork. 


\section{REFERENCES}

(1) Barth, J. V.; Constantini, G.; Kern, K. Nature 2005, 437, 671-679.

(2) Liang, M. M.; Guo, L. H. I. Nanosci. Nanotechnol. 2009, 9, 2283-2289.

(3) Goldberg, M.; Langer, R.; Jia, X. Q. J. Biomat. Sci., Pol. Ed. 2007, $18,241-268$.

(4) Gao, J. H.; Xu, B. Nano Todav 2009, 4, 37-51.

(5) Mao, S. S.; Chen, X. B. Int. I. Energy Res. 2007, 31, 619-636.

(6) Cioffi, N.; Torsi, L.; Losito, I.; Di Franco, C.; De Bari, I.; Chiavarone, L.; Scamarcio, G.; Tsakova, V.; Sabbatini, L.; Zambonin, P. G. I. Mater. Chem. 2001, 11, 1434-1440.

(7) Sarkar, D. K.; Zhou, X. J.; Tannous, A.; Leung, K. T. I. Phvs. Chem. B 2003, 107, 2879-2881.

(8) Sarkar, D. K.; Zhou, X. J.; Tannous, A.; Louie, M.; Leung, K. T. Solid State Commun. 2003, 125, 365-368.

(9) Zhou, X. J.; Harmer, A. J.; Heinig, N. F.; Leung, K. T. Langmuir 2004, 20, 5109-5113.

(10) Xu, J.; Tang, Y. B.; Zhang, W. X.; Lee, C. S.; Yang, Z. H.; Lee, S. T. Crust. Growth Des. 2009, 9, 4524-4528.

(11) Zhang, Y. J.; Or, S. W.; Wang, X. L.; Cui, T. Y.; Cui, W. B.; Zhang, Y.; Zhang, Z. D. Eur. J. Inorg. Chem. 2009, 168-173.

(12) Liu, J. P.; Huang, X. T.; Li, Y. Y.; Sulieman, K. M.; He, X.; Sun, F. L. I. Mater. Chem. 2006, 16, 4427-4434.

(13) Lai, C. X.; Wu, Q. B.; Chen, J.; Wen, L. S.; Ren, S. Nanotechnology 2010, 21, 215602

(14) Wang, Y. J.; Tsai, A. T.; Yang, C. S. Mater. Lett. 2009, 63, 847-849.

(15) Xu, K. J.; Ding, W. P. Mater. Lett. 2008, 62, 4437-4439.

(16) Zhang, X.; Guo, Y. G.; Zhang, P. Y.; Wu, Z. S.; Zhang, Z. I. Mater. Lett. 2010, 64, 1200-1203.

(17) Dubal, D. P.; Dhawale, D. S.; Salunkhe, R. R.; Jamdade, V. S.; Lokhande, C. D. I. Allovs Compd. 2010, 492, 26-30.

(18) Zhang, Y.; He, X. L.; Li, J. P.; Zhang, H. G.; Gao, X. G. Sens. Actuators, B 2007, 128, 293-298.

(19) Cao, A. M.; Monnell, J. D.; Matranga, C.; Wu, J. M.; Cao, L. L.; Gao, D. I. Phvs. Chem. C 2007, 111, 18624-18628.

(20) Guo, Z. G.; Liu, W. M.; Su, B. L. Appl. Phys. Lett. 2008, 92, 063104

(21) Xiang, J. Y.; Tu, J. P.; Zhang, L.; Zhou, Y.; Wang, X. L.; Shi, S. I. Electrochim. Acta 2010, 55, 1820-1824.

(22) Kwak, C. H.; Cho, I. S.; Lee, S.; An, J. S.; Hong, K. S. I. Nanosci. Nanotechnol. 2010, 10, 1185-1190.

(23) Xu, J. S.; Xue, D. F. I. Phys. Chem. B 2005, 109, 17157-17161.

(24) Guo, Z. G.; Fang, J.; Hao, J. C.; Liang, Y. M.; Liu, W. M. ChemPhysChem 2006, 7, 1674-1677.

(25) Carbajal Arizaga, G. G.; Satyanarayana, K. G.; Wypych, F Solid State Ion. 2007, 178, 1143-1162.

(26) Hepel, M.; Chen, Y. M.; Stephenson, R. Electrochem. Soc. Proc. 1994, 31, 304-319.

(27) Hepel, M.; Chen, Y. M.; Adams, L. Proc. AESF Ann. Technol. Conf. 1995, 82, 709-720.

(28) Hepel, M.; Chen, Y. M.; Stephenson, R. I. Electrochem. Soc. 1996, 143, 498-505.

(29) Liu, Y. C.; Hwang, B. J. I. Electroanal. Chem. 2001, $501,100-106$

(30) Liu, Y. C.; Hwang, B. I. Thin Solid Films 1999, 339, 233-239.

(31) Li, S.; Qiu, Y. B.; Guo, X. P. React. Funct. Polvm. 2009, 69, 743-749.

(32) Inoue, M. B.; Nebesny, K. W.; Fernando, Q.; Castilloortega, M. M.; Inoue, M. Synth. Met. 1990, 38, 205-212.

(33) Ohkubo, Y.; Onishi, S.; Ohtake, T.; Ogawa, K. I. Chem. Eng. Inn. 2010, 43, 406-412.

(34) Watanabe, N.; Morais, J.; Alves, M. C. M. L.Phvs. Chem. B 2002, 106, 11102-11107.

(35) Alves, M. C. M.; Watanabe, N.; Ramos, A. Y.; Tolentino, H. C. N. I. Sunchrotr. Radiat. 2001, 8, 517-519.
(36) Baker, C. K.; Qiu, Y. J.; Reynolds, J. R. I. Phvs. Chem. 1991, 95, 4446-4452.

(37) Weidlich, C.; Mangold, K. M.; Juttner, K. Electrochim. Acta 2005, 50, 1547-1552.

(38) Salzer, C. A.; Elliot, C. M.; Hendrickson, S. M. Anal. Chem. 1999, 71, 3677-3683.

(39) Sin, S. L.; Teo, L. L.; Tan, K. S.; Chan, C. Y. Electrochem. Commun. 2000, 2, 685-691.

(40) Holzhauser, P.; Bouzek, K. I. Appl. Electrochem. 2006, $36,703-710$.

(41) Armstrong, R. D.; Harrison, J. A. I. Electrochem. Soc. 1969, $116,328-331$.

(42) Norskov, J. K.; Rossmeisl, J.; Logadottir, A.; Lindqvist, L.; Kitchin, J. R.; Bligaard, T.; Jonsson, H. I. Phys. Chem. B 2004, 108, 17886-17892.

(43) Jakobs, R. C. M.; Janssen, L. J. J.; Barendrecht, E. Electrochim. Acta 1985, 30, 1085-1091.

(44) Jakobs, R. C. M.; Janssen, L. J. J.; Barendrecht, E. Electrochim. Acta 1985, 30, 1433-1439.

(45) Secco, E. A. Can. I. Chem.-Rev. Can. Chim. 1988, 66, 329-336.

(46) Ramamurthy, P.; Secco, E. A. Can. I. Chem. 1970, $48,3510-3519$.

(47) Omori, K.; Kerr, P. F. Geol. Soc. Am. Bull. 1963, 74, 709-734.

(48) Kautek, W.; Gordon, J. G. L. Electrochem. Soc. 1990, $137,2672-2677$.

(49) Hayez, V.; Franquetl, A.; Hubin, A.; Terryn, H. Surf. Interface Anal. 2004, 36, 876-879.

(50) Hwang, I. C.; Woo, S. I. I. Phvs. Chem. B 1997, 101, 4055-4059.

(51) Klein, J. C.; Chung, P. L.; Hercules, D. M.; Black, J. F. Appl. Spectrosc. 1984, 38, 729-734.

(52) Klein, J. C.; Proctor, A.; Hercules, D. M.; Black, J. F. Anal. Chem. 1983, 55, 2055-2059.

(53) Zotti, G.; Zecchin, S.; Schiavon, G.; Louwet, F.; Groenendaal, L.; Crispin, X.; Osikowicz, W.; Salaneck, W.; Fahlman, M. Macromolecules 2003, 36, 3337-3344.

(54) Nefedov, V. I.; Zhumadilov, E. K.; Kopytova, T. Y. I. Struct. Chem. 1977, 18, 549-553.

(55) Nefedov, V. I.; Salyn, Y. V.; Solozhenkin, P. M.; Pulatov, G. Y. Surf. Interface Anal. 1980, 2, 170-172.

(56) Strohmeier, B. R.; Leyden, D. E.; Field, R. S.; Hercules, D. M. I. Catal. 1985, 94, 514-530.

(57) Ruangchuay, L.; Schwank, J.; Sirivat, A. Appl. Surf. Sci. 2002, 199, 128-137.

(58) Kang, E. T., Neoh, K. G.; Tan, K. L. Photoelectron Spectroscopy of Conducting Polymers, Handbook Of Organic Conductive Molecules and Polymers, Vol. 3, Conductive Polymers: Spectroscopy and Physical Properties; John Wiley \& Sons Ltd.: Chichester, England, 1997.

(59) Liu, Y. C.; Yang, K. H.; Ger, M. D. Sunth. Met. 2002, $126,337-345$

(60) Tan, K. L.; Tan, B. T. G.; Kang, E. T.; Neoh, K. G. I. Chem. Phys. 1991, 94, 5382-5388.

(61) Paunovic, M.; Schlesinger, M. Fundamentals of Electrochemical Deposition; John Wiley \& Sons, Inc.: Hoboken, NJ, 2006.

(62) Yoder, C. H.; Gotlieb, N. R.; Rowand, A. L. Am. Mineral. 2010, $95,47-51$.

(63) Frost, R. L.; Williams, P. A.; Martens, W.; Leverett, P.; Kloprogge, J. T. Am. Mineral. 2004, 89, 1130-1137.

(64) Mrose, M. E. Am. Mineral. 1961, 46, 146-154. 